\title{
Cartilage Oligomeric Matrix Protein in Patients with Juvenile Idiopathic Arthritis: Relation to Growth and Disease Activity
}

\author{
BIRGITTE BJØRNHART, ANDERS JUUL, SUSAN NIELSEN, MAREK ZAK, PERNILLE SVENNINGSEN, \\ and KLAUS MÜLLER
}

\begin{abstract}
Objective. Cartilage oligomeric matrix protein (COMP) has been identified as a prognostic marker of progressive joint destruction in rheumatoid arthritis. In this population based study we evaluated associations between plasma concentrations of COMP, disease activity, and growth velocity in patients with recent-onset juvenile idiopathic arthritis (JIA). COMP levels in JIA and healthy children were compared with those in healthy adults. Plasma levels of insulin-like growth factor I (IGF-1), which has been associated with COMP expression and growth velocity, were studied in parallel.

Methods. 87 patients with JIA entered the study, including oligoarticular JIA $(n=34)$, enthesitis-related arthritis $(n=8)$, polyarticular rheumatoid factor $(R F)$-positive JIA $(n=2)$, polyarticular RF-negative JIA $(n=27)$, systemic JIA $(n=6)$, and undifferentiated JIA $(n=10)$. Plasma levels of COMP were measured by ELISA and IGF-1 by a radioimmunoassay.

Results. Significantly higher COMP levels [mean 18.9 U/1 (95\% CI 17.3-20.5)] were found in healthy children compared with healthy adults [mean 10.7 U/1 (95\% CI 9.4-12.1)] ( $<<0.0001)$. COMP levels in the JIA patients [mean $13.5 \mathrm{U} / 1$ (95\% CI 12.4-14.7)] were significantly reduced compared to healthy children ( $\mathrm{p}<0.0001)$, and correlated negatively with C-reactive protein (CRP; $\mathrm{r}=-0.29, \mathrm{p}=0.01)$ and thrombocyte count $(\mathrm{r}=-0.28, \mathrm{p}=0.02)$. COMP levels in the JIA patients correlated positively with growth velocity $(\mathrm{cm} / \mathrm{yr})(\mathrm{r}=0.38, \mathrm{p}=0.0003)$ and growth velocity $(\mathrm{SDS})$ ( $\mathrm{r}=0.29, \mathrm{p}=0.007)$.

Conclusion. We found reduced COMP levels in children with JIA compared with healthy children. COMP levels in JIA correlated negatively with inflammatory activity as evaluated by CRP and the thrombocyte counts, and were associated with reduced growth rate. (First Release July 15 2009; J Rheumatol 2009;36:1749-54; doi:10.3899/jrheum.080942)
\end{abstract}

Key Indexing Terms:

CARTILAGE OLIGOMERIC MATRIX PROTEIN

INSULIN-LIKE GROWTH FACTOR I

GROWTH

JUVENILE IDIOPATHIC ARTHRITIS

Juvenile idiopathic arthritis (JIA) is a heterogeneous group of chronic arthritides of childhood that vary from a mild disease subsiding in puberty to a progressive disease that can cause severe articular damage and growth disorders ${ }^{1-3}$. Cartilage oligomeric matrix protein (COMP) is a $524-\mathrm{kDa}$ noncollagenous glycoprotein and a member of the throm-

From Paediatric Clinic II and Department for Growth and Reproduction, Rigshospitalet National University Hospital, University of Copenhagen, Copenhagen, Denmark.

Supported by the Danish Rheumatism Association, The Dagmar Marshall Foundation, The Research Foundation for Copenhagen, the Faeroe Islands and Greenland, The Queen Ingrid Foundation, The Henriksen Foundation, Director Jacob Madsen's Foundation, The Ville Heise Foundation, and The Holgersen Foundation.

B. Bjфrnhart, MD, Paediatric Clinic II; A. Juul, Professor, Department for Growth and Reproduction; S. Nielsen, MD; M. Zak, MD; P. Svenningsen, MD; K. Müller, MD, PhD, DMSc, Paediatric Clinic II, Rigshospitalet National University Hospital.

Address correspondence to Dr. K. Müller, Paediatric Clinic II, 4072, Rigshospitalet, Blegdamsvej 9, DK-2100 Copenhagen, Denmark.

E-mail:klausmuller@dadlnet.dk

Accepted for publication March 27, 2009. bospondin family $y^{4,5}$. It is found primarily in the extracellular matrix of articular cartilage ${ }^{4}$ but also in tendons ${ }^{6}$ and in meniscus ${ }^{7}$. It binds different collagens, thereby playing a role in the assembly of the extracellular matrix ${ }^{8}$. The protein is released from the synovial fluid into serum, where it can be measured.

Plasma levels of COMP have been found to be elevated in a number of conditions characterized by joint destruction and joint inflammation, including rheumatoid arthritis (RA) and osteoarthritis ${ }^{7,9,10}$. In RA, COMP has been identified as a prognostic marker of progressive joint destruction ${ }^{7,10-13}$.

Few studies have investigated COMP in JIA ${ }^{9,14-16}$. COMP has been found to be lower in JIA compared to healthy controls ${ }^{9,14,15}$, and a study of 11 JIA patients with systemic disease suggested that reduced COMP concentration could be a useful marker of active disease ${ }^{14}$. Thus, treatment with the interleukin 6 (IL-6) antagonist tocilizumab was associated with an increase in COMP concentrations ${ }^{14}$. Similarly, a study of 68 JIA patients indicated that reduced COMP levels may reflect the severity of disease ${ }^{16}$. 
However, growth impairment was not investigated in these 2 studies.

Our aim was to evaluate associations between plasma levels of COMP and disease activity and growth velocity in recent-onset JIA. Growth velocity and plasma levels of insulin-like growth factor I (IGF-I), which have been associated with COMP expression ${ }^{17}$, were studied in parallel $^{18}$.

\section{MATERIALS AND METHODS}

Patients. In this population-based study, patients from east Denmark diagnosed with JIA according to the Edmonton criteria ${ }^{19}$ and with disease onset between January 1997 and November 2001 were consecutively included. Eighty-seven children with JIA ( 64 girls, 23 boys) with mean age at disease onset of 6.9 years (95\% CI 6.0-7.7) were included. The mean time from disease onset to inclusion was 1.1 years (95\% CI 0.9-1.3). Six patients had systemic-onset disease; 2 had IgM rheumatoid factor (RF)-positive polyarticular onset type; 27 had RF-negative polyarticular-onset disease; 34 had oligoarticular-onset JIA; 8 had enthesitis-related arthritis; and 10 had undifferentiated JIA. Sixteen patients were HLA-B27-positive. Medical treatment at the time of sampling included methotrexate $(n=12)$, sulfasalazine $(n=20)$, prednisolone $(n=11)$, hydroxychloroquine $(n=3)$, cyclosporin A $(\mathrm{n}=1)$, and nonsteroidal antiinflammatory drugs $(\mathrm{n}=71$; Table 1$)$.

Controls. Controls were healthy children and adults. The children $(\mathrm{n}=38$; 19 male) had a mean age of 9.2 years ( $95 \%$ CI 8.0-10.5), and the adults ( $\mathrm{n}$ =18) a mean age of 39.1 years (95\% CI 34.5-43.7).

Clinical variables. Patients were assessed at time of inclusion. The following clinical measures were recorded: number of active joints as defined by the American College of Rheumatology pediatric criteria [presence of swelling (not due to currently inactive synovitis or to bony enlargement) or, if no swelling is present, limitation of motion accompanied by heat, pain, or tenderness ${ }^{20}$ ], early morning stiffness, Childhood Health Assessment Questionnaire, C-reactive protein (CRP), and thrombocyte counts. Pain score, patient/parent global assessment, and physician's global assessment were graded on a visual analog scale with maximum at $100 \mathrm{~mm}$ (Table 2). Plasma samples. EDTA blood was taken at the time of inclusion and centrifuged within $10 \mathrm{~min}$ after collection, and the plasma was stored at $-80^{\circ} \mathrm{C}$. COMP measurement. COMP was measured by a commercial sandwich-ELISA (AnaMar Medical, Uppsala, Sweden) according to the instructions of the manufacturer. Intra- and interassay variations were $1.7 \%-3.0 \%$ and $1.8 \%-4.2 \%$, respectively (studies performed by AnaMar Medical).

Although some studies have documented that intense physical exercise is associated with a transient increase in serum COMP levels in patients with osteoarthritis, the design of our study was not standardized with respect to this variable ${ }^{21}$.

Insulin-like growth factor I. IGF-I was measured in all subjects by a radioimmunoassay ${ }^{22}$. In brief, serum was extracted by acid/ethanol and cryoprecipitate prior to analysis in order to remove interfering binding proteins, and monoiodinated Tyr31-[ $\left.{ }^{125} \mathrm{I}\right]$ des-(1-3) IGF-I was used as a radioligand. Inter- and intraassay variations were $8.7 \%$ and $3.9 \%$ (at B/B0 of $0.4)$, respectively. The limit of detection was $21 \mathrm{ng} / \mathrm{ml}$.

Growth velocity. Height was measured by the same investigator using a wall-mounted stadiometer, at the time of inclusion and at followup after a mean period of 196 days (95\% CI 182.9-209.1). Growth velocity was calculated as the differences in height between the 2 measurements divided by the time between the assessments (expressed as $\mathrm{cm} / \mathrm{yr}$ ). Further, growth velocity standard deviation score (SDS) was calculated from age- and sex-related normative data, using Growth Vision software (Novo Nordisk, Bagsværd, Denmark).

Statistics. Data are given as mean and 95\% confidence intervals. Differences were evaluated by the Mann-Whitney test and the Kruskal-Wallis test, and for correlation analysis the Spearman test was applied. The correlation between COMP and age, sex, and presence or absence of JIA was analyzed further using a general linear model (GLM). The 5\% level of significance was chosen. Statistical analyses were carried out using SPSS, version 15 (SPSS, Cary, IL, USA).

The study was approved by the regional ethics committee.

\section{RESULTS}

Characteristics and disease activity measures of the JIA patients are summarized in Tables 1 and 2 .

COMP levels in healthy children, adults, and JIA. COMP levels were found at significantly higher levels in healthy children compared with healthy adults $(\mathrm{p}<0.0001$; Figure 1). There was a trend toward higher levels of COMP in children within the age range of 10-14 years (Figure 2).

COMP levels in the patients with JIA were significantly reduced compared with those in healthy children $(\mathrm{p}<$ 0.0001; Figure 1). In accord with the findings in healthy children, plasma levels of COMP tended to be higher within the age range of 10-14 years in JIA patients (Figure 2). In addition, JIA patients had significantly lower COMP levels compared with controls after controlling for age and sex in a multivariate analysis (GLM). There was no significant dif-

Table 1. Characteristics of healthy children and patients with juvenile idiopathic arthritis (JIA) ( $\mathrm{n}=87)$ according to age, sex, onset type, and medical treatment at time of inclusion.

\begin{tabular}{|c|c|c|c|c|}
\hline & $\begin{array}{c}\text { Age, yrs } \\
\text { mean }(95 \% \mathrm{CI})\end{array}$ & Sex & $\begin{array}{c}\text { Onset Type, } \\
\text { no., } \mathrm{n}=87\end{array}$ & $\begin{array}{c}\text { Medical Treatment, } \\
\text { no., } \mathrm{n}=84\end{array}$ \\
\hline JIA & $6.9(6.0-7.7)$ & $\begin{array}{l}64 \text { girls, } \\
23 \text { boys }\end{array}$ & $\begin{array}{c}\text { Oligoarticular (64) } \\
\text { ERA (8) } \\
\text { Polyarticular RF + (2) } \\
\text { Polyarticular RF - (27) } \\
\text { Systemic (6) } \\
\text { Undifferentiated (10) }\end{array}$ & $\begin{array}{c}\text { MTX (12) } \\
\text { Sulfasalazine (20) } \\
\text { Hydroxychloroquine (3) } \\
\text { Cyclosporin A (1) } \\
\text { Prednisolone (11) } \\
\text { NSAID (71) }\end{array}$ \\
\hline $\begin{array}{l}\text { Healthy } \\
\text { children }\end{array}$ & $9.2(8.0-10.5)$ & $\begin{array}{l}19 \text { girls, } \\
19 \text { boys }\end{array}$ & NA & NA \\
\hline
\end{tabular}

NSAID: nonsteroidal antiinflammatory drugs; MTX: methotrexate; RF: IgM rheumatoid factor; ERA: enthesitis-related arthritis, NA: not applicable. 
Table 2. Disease activity variables in patients with juvenile idiopathic arthritis.

\begin{tabular}{lc}
\hline Variable & Mean $(95 \% \mathrm{CI})$ \\
\hline CRP, mg/1 & $10.7(4.4-16.9)$ \\
Physician global assessment, 100 mm VAS & $20.0(16.6-23.5)$ \\
Patient global assessment, 100 mm VAS & $15.5(11.4-19.6)$ \\
CHAQ, units & $0.5(0.4-0.6)$ \\
Joint score, $\mathrm{n}$ & $3.4(2.3-4.4)$ \\
Thrombocyte count, $10^{6} / 1$ & $362.0(336-387)$ \\
\hline
\end{tabular}

CRP: C-reactive protein; VAS: visual analog scale; CHAQ: Childhood Health Assessment Questionnaire.

ference between COMP levels in the different onset types of JIA or between boys and girls (data not shown).

COMP correlated negatively with CRP and with thrombocyte counts, but did not correlate with other markers of disease activity (Table 3 ).

COMP and growth velocity. COMP levels in the JIA patients correlated positively with growth velocity $(\mathrm{cm} / \mathrm{yr})(\mathrm{r}=0.38$, $\mathrm{p}=0.0003$; Figure 3 ). This association persisted after correction for age and sex in a multivariate analysis (GLM). For analysis of associations between COMP and the degree of growth retardation the SDS for growth velocity were calculated based on data from healthy children. A positive correlation was found between growth velocity SDS and $\operatorname{COMP}(r=0.29 ; p=0.007)$. Similarly, growth velocity SDS was significantly associated with COMP in a GLM analysis that included age and sex as covariates. Moreover, growth velocity SDS was found to correlate negatively with the $\mathrm{CRP}(\mathrm{r}=-0.24, \mathrm{p}=0.03)$, but did not correlate significantly with any other clinical or paraclinical measures of disease activity.

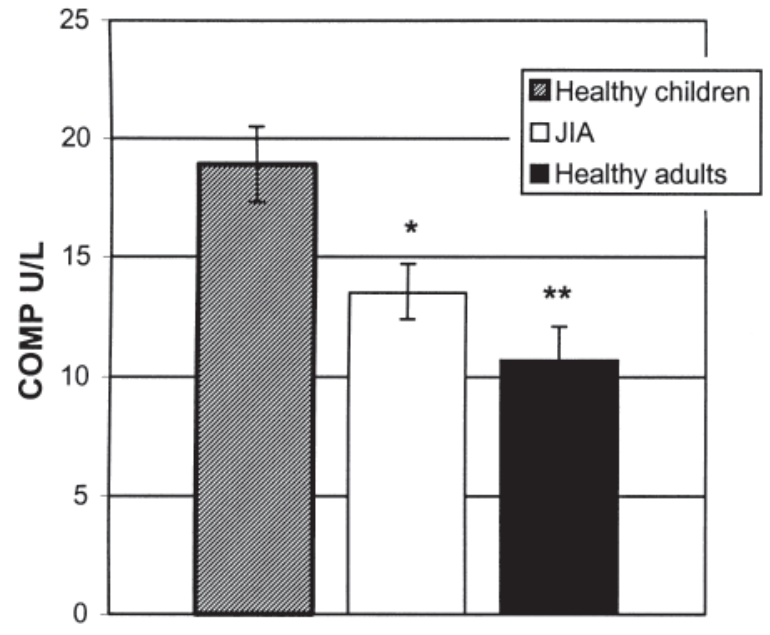

Figure 1. Cartilage oligomeric matrix protein (COMP) levels in healthy children, patients with JIA, and healthy adults (mean and 95\% CI). Levels in healthy children were significantly higher than those in JIA $(* \mathrm{p}<$ $0.0001)$ and in healthy adults $(* * p<0.0001)$.
IGF-I in patients with JIA. To pursue the relation between COMP levels and growth, IGF-I levels were measured. In general, the level of IGF-I in the JIA patients tended to be in the lower range for healthy children (Figure 4$)^{22}$. We found no significant correlation between IGF-I levels and growth velocity or COMP levels. However, IGF-I correlated negatively with CRP ( $\mathrm{r}=-0.24, \mathrm{p}=0.04)$ and thrombocyte counts $(r=-0.43, p=0.0001$; Figure 5).

\section{DISCUSSION}

Serum levels of COMP are elevated in patients with RA ${ }^{11}$ and this is considered a marker of cartilage turnover of prognostic significance in this disease $\mathrm{e}^{7,9,11,12}$.

Our study was undertaken to evaluate the significance of COMP in recent-onset JIA with special emphasis on disease activity and growth impairment. We found significant age-dependent differences in COMP levels, with higher levels in children compared with adults. In patients with JIA, COMP levels were reduced compared with healthy children, and they correlated negatively with disease activity as evaluated by CRP and thrombocyte counts. These findings are in agreement with 2 previous studies of JIA ${ }^{9,15}$.

Growth velocities correlated positively with the COMP levels, suggesting that the COMP level in JIA patients is associated with the rate of growth. As expected, growth velocity was reduced in a proportion of the patients with JIA, and in line with the notion that inflammatory activity in JIA leads to impaired linear growth ${ }^{2,23}$ we also observed a negative correlation between COMP and CRP.

A recent study reported that COMP levels in JIA patients who did not develop joint erosions and joint space narrowing were higher than in patients with progressive joint damage $^{16}$. These results correspond with our finding of a negative correlation between COMP, CRP, and growth velocity.

Growth hormone and IGF-I stimulate bone growth, and IGF-I has been found to induce COMP gene expression in primary cultured human chondrocytes ${ }^{17}$. Further, COMP levels were found to increase after initiation of treatment with growth hormone in short-statured children ${ }^{23}$.

In patients with JIA, IGF-I levels were found to be reduced in relation to inflammation, but in response to treatment with tumor necrosis factor (TNF) antagonist (etanercept), IGF-I increased ${ }^{24}$. In line with this, transgenic mice overexpressing another inflammatory cytokine, IL-6, had decreased IGF-I production ${ }^{25-27}$. Further, a negative correlation between circulating IL- 6 and concentration of IGF-I was found in patients with systemic JIA ${ }^{27}$. Together these studies indicate that IGF-I could represent a link connecting inflammation-induced growth retardation and reduced COMP levels. We found a negative correlation between IGF-I levels and CRP and thrombocyte counts, in keeping with these previous results ${ }^{25}$, also indicating that inflammatory activity may inhibit release of IGF-I. In our study, however, IGF-1 did not correlate with COMP levels or with 


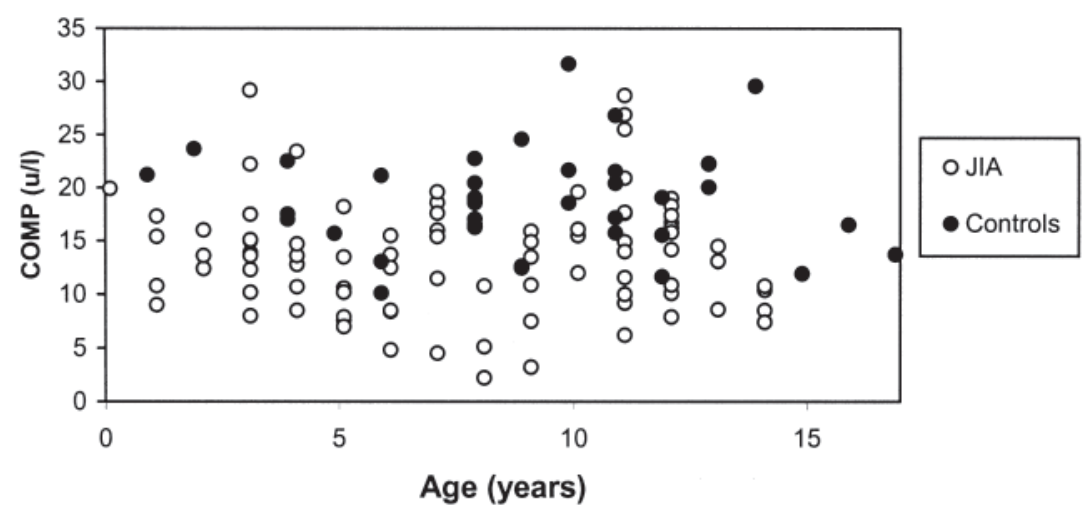

Figure 2. Cartilage oligomeric matrix protein (COMP) levels in healthy children and JIA by age.

Table 3. Association between levels of cartilage oligomeric matrix protein (COMP) and disease activity variables in JIA patients (Spearman correlation coefficient).

\begin{tabular}{lcc}
\hline Variable & $\begin{array}{c}\text { Correlation Coefficient } \\
\text { vs COMP }\end{array}$ & $\mathrm{p}$ \\
\hline CRP & -0.29 & 0.01 \\
Physician global assessment, VAS & -0.08 & $\mathrm{NS}$ \\
Patient global assessment, VAS & -0.03 & $\mathrm{NS}$ \\
CHAQ & -0.12 & $\mathrm{NS}$ \\
Joint score & 0.02 & $\mathrm{NS}$ \\
Thrombocyte count & -0.28 & 0.02 \\
\hline
\end{tabular}

VAS: visual analog scale $100 \mathrm{~mm}$; CRP: C-reactive protein; CHAQ: Childhood Health Assessment Questionnaire.

growth velocity. Therefore, based on our data, it is not likely that IGF-I plays a major role in the regulation of COMP levels or represents a link between growth impairment and reduced COMP levels in these patients.

Proinflammatory cytokines such as TNF- $\alpha$, IL-6, and IL-1 13 have long been known to play a major role in the pathogenesis of JIA. Besides maintaining inflammation they are also thought to contribute to growth impairment in children with chronic inflammatory diseases ${ }^{2,26-29}$. Thus, there is also a question whether there is any direct effect of inflammation on COMP release. The finding of a significant negative correlation between CRP and COMP by us and other investigators would suggest that this is actually the case $^{15}$. However, this appears to contrast with the conclusions from RA studies, where no correlation between CRP and COMP could be shown ${ }^{13,30}$. Since studies indicate that anti-TNF treatment in JIA can restore growth ${ }^{28,29}$, it would be of interest to examine whether anti-TNF treatment in JIA may lead to normalization of COMP levels.

We aimed at studying JIA patients with recent-onset disease, and therefore patients were recruited upon referral. Since reliable height measures were not available in all patients before this time, the calculations of height velocity were based on height measures at the time of referral and about 6 months afterward. Thus, we cannot rule out that this variable may have been influenced by treatment initiated during this time. Studies have shown that corticosteroids reduce COMP levels in rats with collagen-induced arthritis ${ }^{31}$ as well as in patients with RA when administred intravenously ${ }^{30}$ or intraarticularly ${ }^{32}$. However, we did not observe indications of an effect of steroid use, since COMP levels were reduced independently of ongoing steroid treatment.

Another limitation in this study relates to physical activity, which may be of particular interest in an investigation that compares healthy individuals with physically disabled patients. Interestingly, there is evidence that physical exercise is associated with a transient increase in serum COMP levels ${ }^{21}$. The design of our study did not include standardization with respect to physical exercise, and therefore we

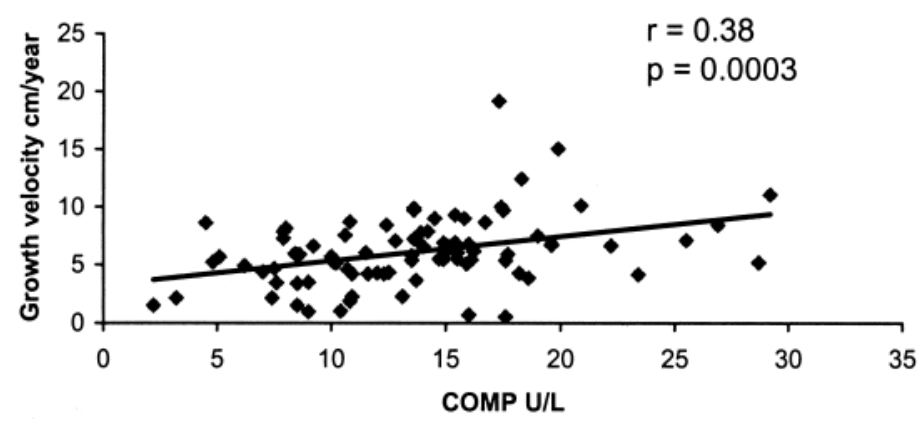

Figure 3. Correlation between growth velocity ( $\mathrm{cm} /$ year) and cartilage oligomeric matrix protein (COMP) levels in JIA. 

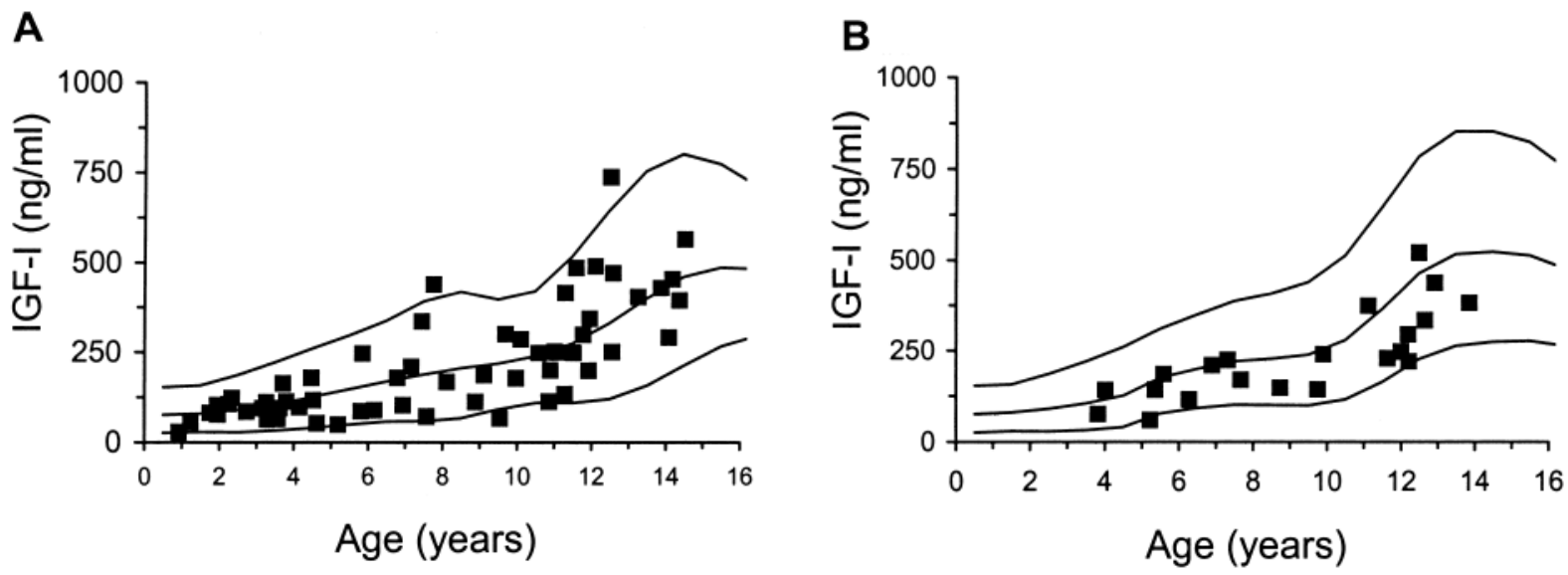

Figure 4. A. Insulin-like growth factor-1 (IGF-1) levels versus age in female patients with JIA. Levels in a control population of healthy children are shown as $0 \pm 2$ SD curves. B. IGF-1 levels versus age in male patients with JIA. Levels in a control population of healthy children are shown as $0 \pm 2 \mathrm{SD}$ curves.

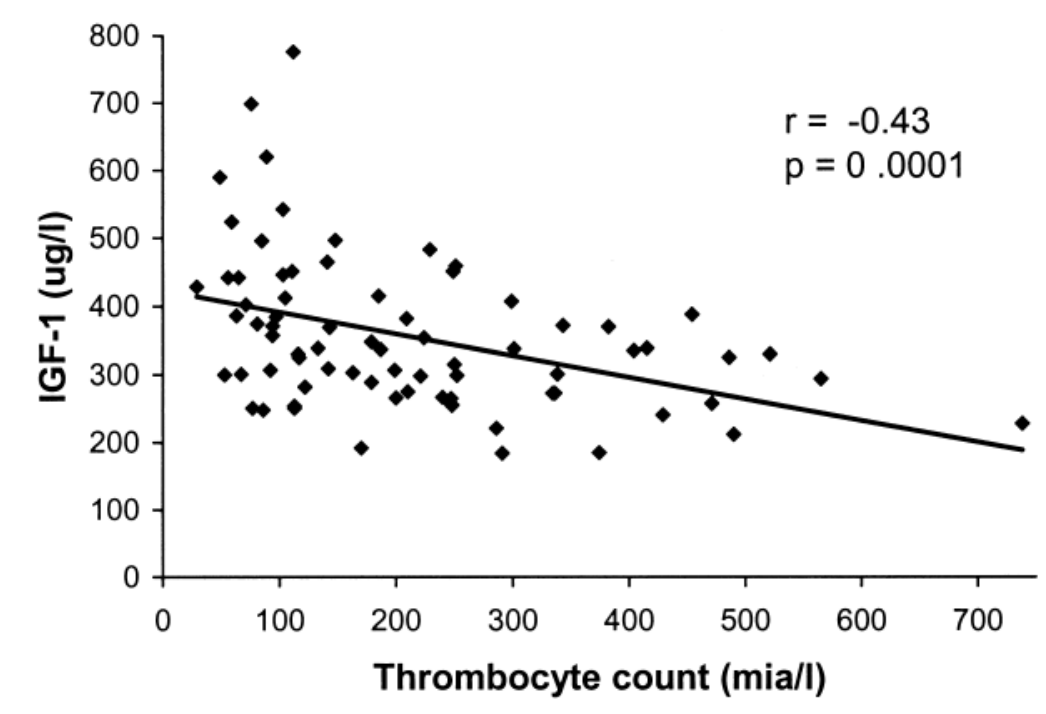

Figure 5. Insulin-like growth factor-1 (IGF-1) and thrombocyte count in patients with JIA.

cannot exclude that differences in physical activity could have influenced the results.

We found reduced COMP levels in our cohort of 87 well characterized children with JIA compared with healthy children. This reduction was most likely secondary to the reduced growth rate observed in these children. Future studies should address whether COMP might be useful as a prognostic marker in JIA with respect to the risk of severe growth impairment.

\section{ACKNOWLEDGMENT}

We are grateful to The East Danish Paediatric Rheumatology Research Group for participating in the study.

\section{REFERENCES}

1. Cassidy JT, Petty RE. Juvenile rheumatoid arthritis. In: Cassidy JT, Petty RE, editors. Textbook of pediatric rheumatology. Philadelphia: WB Saunders Company; 1997:133-233.

2. MacRae VE, Farquharson C, Ahmed SF. The pathophysiology of the growth plate in juvenile idiopathic arthritis. Rheumatology 2006; $45: 11-9$

3. Liem JJ, Rosenberg AM. Growth patterns in juvenile rheumatoid arthritis. Clin Exp Rheumatol 2003;21:663-8.

4. Hedbom E, Antonsson P, Hjerpe A, et al. Cartilage matrix proteins, an acidic oligomeric protein (COMP) detected only in cartilage. J Biol Chem 1992;267:6132-6.

5. Newton G, Weremowicz S, Morton C, et al. Characterization of human and mouse cartilage oligomeric matrix protein. Genomics 1994;24:435-9.

$$
\text { Personal non-commercial use only. The Journal of Rheumatology Copyright (C) 2009. All rights reserved. }
$$


6. DiCesare P, Hauser N, Lehman D, Pasumarti S, Paulsson M. Cartilage oligomeric matrix protein (COMP) is an abundant component of tendon. FEBS Lett 1994;354:237-40.

7. Neidhart M, Hauser N, Paulsson M, DiCesare PE, Michel DA, Häuselmann HJ. Small fragments of cartilage oligomeric matrix protein in synovial fluid and serum as markers for cartilage degradation. Br J Rheumatol 1997;36:1151-60.

8. Hecht JT, Hayes E, Haynes R, Cole WG. COMP mutations, chondrocyte function and cartilage matrix. Matrix Biol 2005;23:525-33.

9. Saxne T, Heinegård D. Cartilage oligomeric matrix protein: a novel marker of cartilage turnover detectable in synovial fluid and blood. Br J Rheumatol 1992;31:583-91.

10. Wislowska M, Jablonska B. Serum cartilage oligomeric matrix protein (COMP) in rheumatoid arthritis and knee osteoarthritis. Clin Rheumatol 2005;24:278-84.

11. Forslind K, Eberhardt K, Jonsson A, Saxne T. Increased serum concentrations of cartilage oligomeric matrix protein. A prognostic marker in early rheumatoid arthritis. Br J Rheumatol 1992;31:593-8.

12. Lindquist E, Eberhardt K, Bendtzen K, Heinegård D, Saxne T. Prognostic laboratory markers of joint damage in rheumatoid arthritis. Ann Rheum Dis 2005;64:196-201.

13. Crnkic M, Månsson B, Larsson L, Geborek P, Heinegård D, Saxne T. Serum cartilage oligomeric matrix protein (COMP) decreases in rheumatoid arthritis patients treated with infliximab or etanercept. Arthritis Res Ther 2003;5:R181-R185.

14. Nakajima $S$, Naruto T, Miyamae T, et al. Improvement of reduced cartilage oligomeric matrix protein in systemic juvenile idiopathic arthritis patients treated with the anti-interleukin- 6 receptor monoclonal antibody tocilizumab. Mod Rheumatol 2009;19:42-6.

15. Urakami T, Manki A, Inoue T, Oda M, Tanaka H, Morishima T. Clinical significance of decreased serum concentration of cartilage oligomeric matrix protein in systemic idiopathic arthritis. J Rheumatol 2006;33:996-1000.

16. Gilliam BE, Chauhan AK, Low JM, Moore TL. Measurement of biomarkers in juvenile idiopathic arthritis patients and their significant association with disease severity: a comparative study. Clin Exp Rheumatol 2008;26:492-7.

17. Tian H, Stogiannidis I. Up-regulation of cartilage oligomeric matrix protein gene expression by insulin-like growth factor-1 revealed by real-time reverse transcription-polymerase chain reaction. Acta Biochim Biophys Sin 2006;38:677-82.

18. Bechtold S, Ripperger P, Mühlbayer D, et al. GH therapy in juvenile chronic arthritis: results of a two-year controlled study on growth and bone. J Clin Endoclinol Metab 2001;86:5737-44.

19. Petty ER, Southwood TR, Manners P, et al. International League of Associations for Rheumatology classification of juvenile idiopathic arthritis: second revision, Edmonton 2001. J Rheumatol 2004;31:390-2.
20. Giannini EH, Ruperto N, Ravelli A, Lovell DJ, Felson DT, Martini A. Preliminary definition of improvement in juvenile arthritis. Arthritis Rheum 1997;40:1202-9.

21. Andersson MLE, Thorstenssin CA, Roos EM, Peterson IF, Heinegård D, Saxne T. Serum levels of cartilage oligomeric matrix protein (COMP) increase temporarily after physical exercise in patients with knee osteoarthritis. BMC Musculoskel Disord 2006;7:98.

22. Juul A, Bang P, Hertel NT, et al. Serum insulin-like growth factor-I (IGF-I) in 1030 healthy children, adolescents and adults; relation to age, sex, stage of puberty, testicular size and body mass index. J Clin Endocrinol Metab 1994;78:744-52.

23. Bjarnason R, Andersson B, Kim HS, et al. Cartilage Oligomeric Matrix Protein increases in serum after the start of growth hormone treatment in prepubertal children. J Clin Endocrinol Metab 2004;89:5156-60.

24. Schmeling H, Seliger E, Horneff G. Growth reconstitution in juvenile idiopathic arthritis treated with etanercept. Clin Exp Rheumatol 2003;21:779-84

25. De Benedetti F, Alonzi T, Moretta A, et al. Interleukin 6 causes growth impairment in transgenic mice through a decrease in insulin-like growth factor-1: A model for stunted growth in children with chronic inflammation. Clin Invest Med 1997;99:643-50.

26. De Benedetti F, Meazza C, Oliveri M, et al. Effect of IL-6 on IGF-binding protein-3: A study in IL-6 transgenic mice and in patients with systemic juvenile idiopathic arthritis. Endocrinology 2001;142:4818-26.

27. De Benedetti F, Meazza C, Martini A. Role of interleukin-6 in growth failure: An animal model. Horm Res 2002;58 Suppl 1:24-7.

28. Tynjala P, Lahdenne P, Vähäsalo P, Kautiainen H, Honkanen V. Impact of anti-TNF treatment on growth in severe juvenile idiopathic arthritis. Ann Rheum Dis 2006;65:1044-9.

29. Broeder AA, Joosten LAB, Saxne T, et al. Long term anti-tumour necrosis factor alfa monotherapy in rheumatoid arthritis: effect on radiological course and prognostic value of markers of cartilage turnover and endothelial activation. Ann Rheum Dis 2002;61:311-8.

30. Skoumal M, Haberhauer G, Feyertag J, Kittl EM, Bauer K, Dunky A. Serum levels of cartilage oligomeric matrix protein (COMP): a rapid decrease in patients with active rheumatoid arthritis undergoing intravenous steroid treatment. Rheumatol Int 2006;26:1001-4.

31. Larsson E, Erlandsson H, Larsson A, Månsson B, Saxne T, Klareskog L. Corticosteroid treatment of experimental arthritis retards cartilage destruction as determined by histology and serum COMP. Rheumatology 2004;43:428-34.

32. Weitoft T, Larsson A, Saxne T, Rönnblom L. Changes of cartilage and bone markers after intraarticular glucocorticoid treatment with and without postinjection rest in patients with rheumatoid arthritis. Ann Rheum Dis 2005;64:1750-3. 